\title{
Study of Knowledge Management Frameworks
}

\author{
Dipali P. Meher ${ }^{1}$, Dr. Nilesh Mahajan ${ }^{2}$ \\ ${ }^{1}$ Research Scholar, IMED, Bharati Vidyapeeth Deemed University, Pune \\ Assistant Professor, Modern College, Ganeshkhind, Pune 411038, India \\ ${ }^{2}$ Professor, IMED, Bharati Vidyapeeth Deemed University, Pune 411038, India
}

\begin{abstract}
Knowledge management has one simple term behind it: knowledge is a property of individuals and not that of organization. Information is increasing at speedy rate in 21 st century but the rate of knowledge generation is comparatively low. To survive in the rapid changing environment of information technology, organizations have to explicitly manage their knowledge. It is always seen that managed knowledge will result in increased performance of an organization. There are different components of knowledge management. Organizations have created knowledge management framework according their requirements. Every organization is having different framework for knowledge management. This paper will give brief idea about various knowledge management frameworks in different organizations.
\end{abstract}

Keywords: knowledge, knowledge management; knowledge management frameworks

\section{Introduction}

Knowledge Management $(\mathrm{KM})$ is the management of organizational information and knowledge by applying skills, experience, innovation and intelligence. Wiig (1996) defines knowledge as "the insights, understandings and the practical know-how that we all possess" [1].

There is always need of effective KM. Research has shown that there are number of tools and strategies for KM but still, $\mathrm{KM}$ efforts were futile. There are two reasons for this. One, as available softwares do not consider psychological and organizational aspects of KM that has been used and another is, existing software components are not tangible for upcoming barriers of information flow. Organizations have to timely respond to the requirements of stakeholders. For this activity, need of KM must be identified and circulated effectively. So, there is need of different KM initiatives which are key assets of KM framework. The KM initiatives are based on people, process and technology. To study for different KM initiatives different Knowledge Management frameworks will be studied first.

\section{Knowledge Management Frameworks}

There are several KM frameworks at European Guide to Good Practice in KM studied by peter heisig in 2002 to provide holistic view and address all stake holders SMEs and large organizations, consultants and academics and vendors [2][22].

Following is the brief explanation of KM frameworks.

1) European KM Framework: This framework is based on empirical research and practical experience in the field of $\mathrm{KM}$. This framework is divided into three layers.

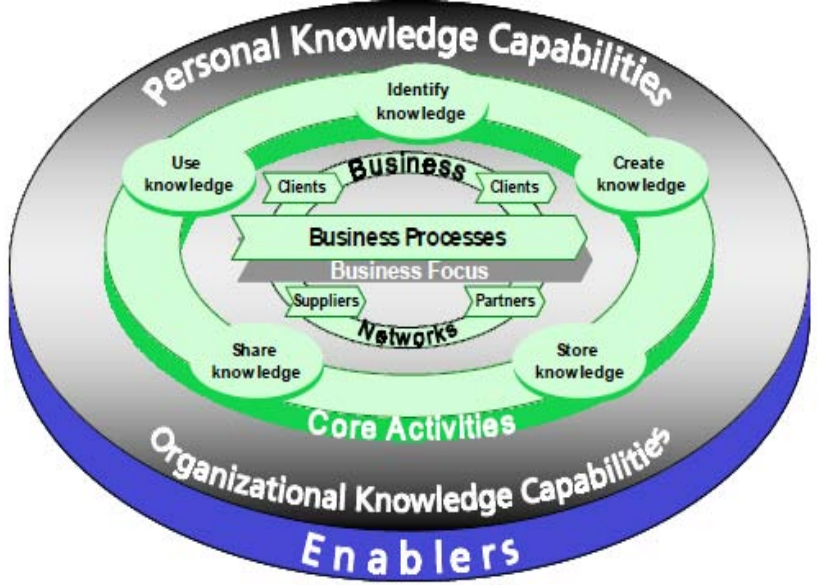

Figure 1: European KM Framework

a) Business focus: It is the centre of $\mathrm{KM}$ and it plays key role in value adding process of an organization. Such processes are strategy development, product/service innovation and development, manufacturing and service delivery, sales and customer support. All these processes contain critical knowledge about the processes and products. b) Core knowledge activities: These activities are identify, create, store, share and use of knowledge. They support wider business processes by applying right KM methods, tools and software $\mathrm{se}$ [3].

c) Enablers: This is the third layer and it consists of two main categories namely personal and organizational knowledge capabilities. Personal capabilities include ambition, skills, behaviour, experience, tools, time management which are developed at group level for the improvements of knowledge handling. Organizational knowledge capabilities are introduced by leader for effective knowledge handling within value added process by internal and external stake holders such as employees, clients, suppliers. This capability involves knowledge assets [2].

2) KM framework at Accenture: This framework is based on share point technology and it provides central access to knowledge, meta data, content management through implementation on web portal. 


\section{International Journal of Science and Research (IJSR) \\ ISSN (Online): 2319-7064}

Index Copernicus Value (2013): 6.14 | Impact Factor (2015): 6.391

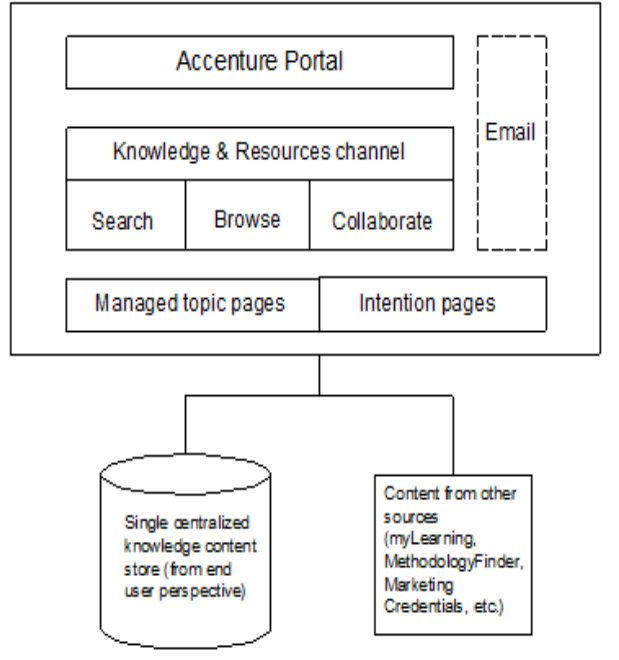

Figure 2: KM framework at Accenture

The components of this architecture are as follows.

a) Accenture Portal: This gives single point of entry to all stakeholders.

b)Knowledge and Resources Channel: This is simple user interface which satisfy user information needs.

c) Managed Topic Pages: Here, Web Pages related to different topic are managed

d)Intension Pages: these pages manage navigation of web pages and manage links to various web parts which are of user intension.

e) Single centralized knowledge content store: here, According to end user perspective multiple contents storage sites are consolidated into single content.

f) Content from other resources: contents from other web sites of user interest will bring into picture.

g)E-mail: with all this emailing facility is given in the same portal for exchange of information [4].

3) KM Framework at Lafarge: Knowledge sharing plays an important role in $\mathrm{KM}$ at Lafarge

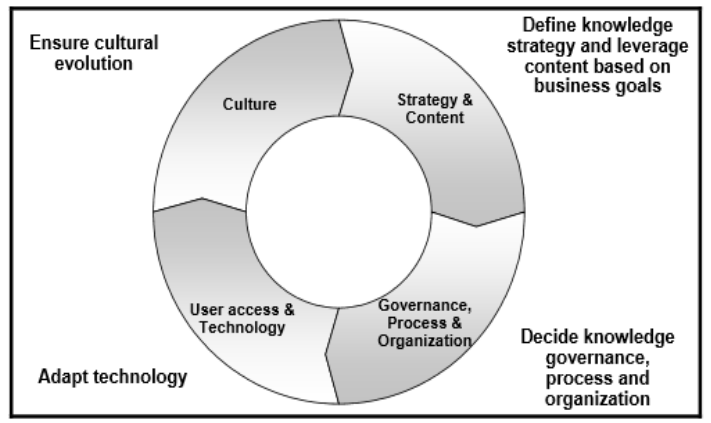

Figure 3: KM framework at Lafarge

The components of framework are as follows:

a) Strategy \& content: It is linked to business activities. According to business goals KM stratergy is designed.

b) Governance, process and organization: this component defines roles and responsibilities of of the members of knowledge sharing project. Process of governance and organization is clearly defined.

c) User access \& technology: It contains network, hardware, software and all the elements for knwoledge sharing projects. Different tools to be designed for simple user acess to the project.

d) Culture: This provides the base to ensure success of KM project. This componenet also ensure that every one involved in knowledge sharing must underatnd the significance of it [5].

4) B. Kari, I toru proposed a framework of KM with 5 components [6].

a) Selectivity- It will determine the important knowledge which is to be forwarded to next generation using template and toolkits.

b) Repurposability- It means reusability of existing knowledge through projects.

c) Interoperability- sharing of knowledge based on experience through community workspace

d) Individual Control and Ownership- sharing of knowledge is under individual ${ }^{\text {ee }} \mathrm{s}$ control/ownership through multilayered knowledge representations.

e) Openness- shared knowledge must made explicit to all through knowledge network.

5) Knowledge Management for semantic web and networking:

This framework is proposed by B. Thuraisingham.

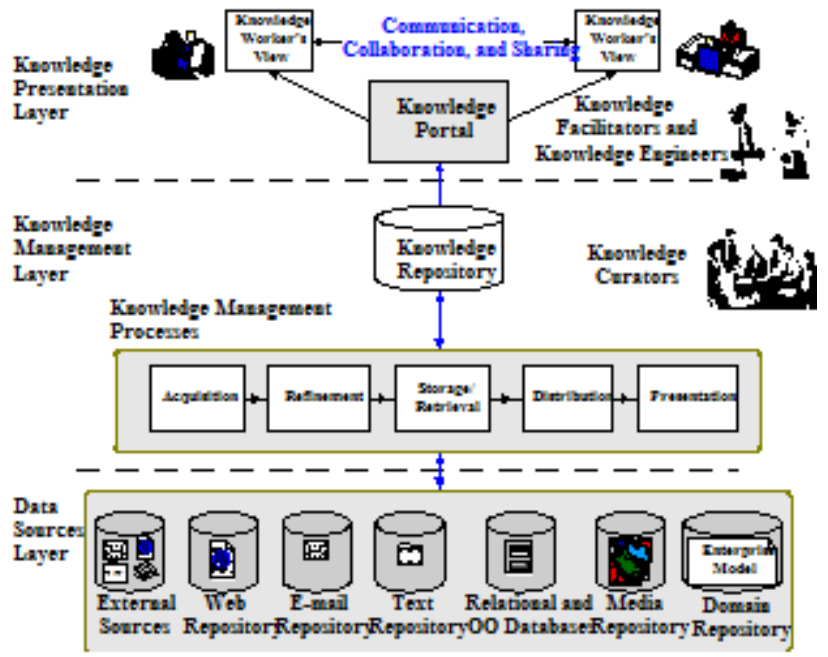

Figure 4: Knowledge Management for semantic web and networking

The three layers of this architecture are explained as follows.

a) Data sources layer: Data is collected from external sources, web repository, emails, texts, relational databases, media, and domain repository.

b) Knowledge management layer: In this layer knowledge repository plays an important role. This layer also contains several KM processes such as acquisition, refinement, storage/retrieval, distribution and presentation. All the services related to data and information such as data mining, Meta data tagging, ontology and taxonomy services, workflow management system, digital rights management, and knowledge creation services. Information integration services such as data warehouse, federation, agent, mediation, security services are managed by this layer.

c) Knowledge presentation and creation layer: Through knowledge portal search services, collaboration and 


\section{International Journal of Science and Research (IJSR) \\ ISSN (Online): 2319-7064 \\ Index Copernicus Value (2013): 6.14 | Impact Factor (2015): 6.391}

message service, video conferencing service, discussion group service, knowledge creation services are provided [7].

6) KM framework at NHS(National Health Service): There are two components as follows.

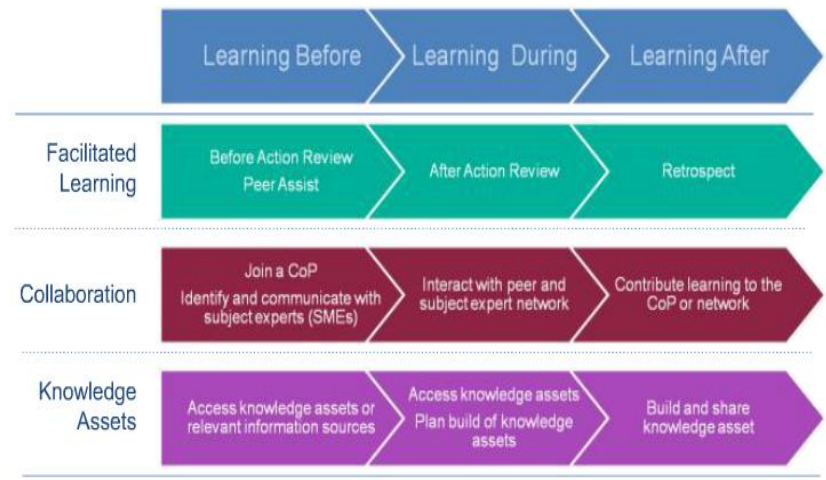

Fig. 5: KM framework at NHS

a) Learning before, learning during and learning after: These activities are individual and contain the lessons learned before during and after execution of $\mathrm{KM}$ process.

b) KM tools and techniques: These contain three activities of KM namely facilitated learning, collaboration and knowledge assets.

Knowledge assets mean publish and share knowledge from harvests and retrospect. Knowledge harvesting means capturing the knowledge of people with vital know how and assets. Retrospect means capturing the knowledge of projects and teams.

Learning before phase will acquire new knowledge. Before action review means to consider what issues might arise and what can be learnt from previous experience. Peer assist means connecting people who have the know-how with the team that want to know.

Communication with subject expert will be done for verification of acquired knowledge [8].

7) BP's knowledge management framework:

BP is the one of the early pioneers in virtual team working and knowledge management.

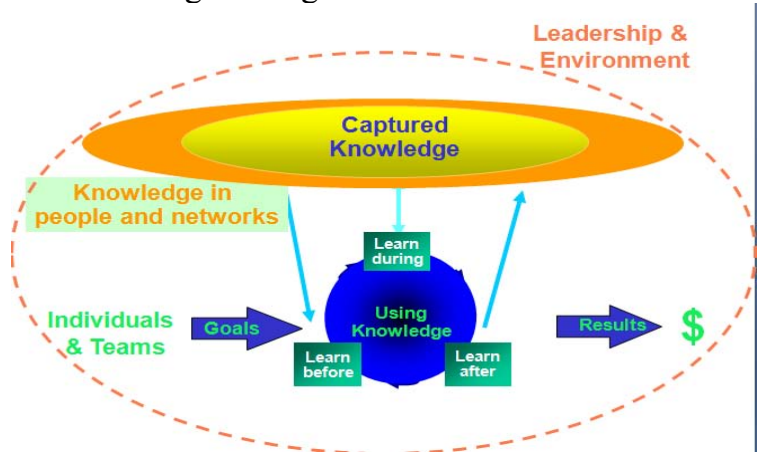

Figure 6: $\mathrm{BP}^{\mathrm{ec}} \mathrm{s}$ knowledge management framework

It comprises of 5 elements:

a) A KM strategy which is part of the organisations strategy

b) The right Leadership \& Environment is needed for successful KM. c) Networks of people well connected to share their knowledge.

d) A discipline of learning before, learning during and learning after in a knowledge management process.

e) Capturing knowledge for reuse to produce new knowledge [9].

\section{8) APO KM Framework: APO (Asian Productivity} Organization)

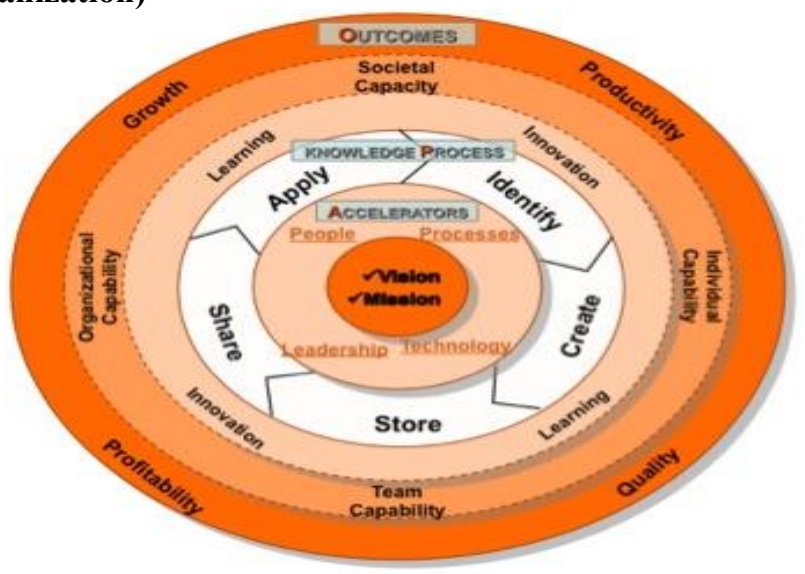

Figure 7: APO KM Framework

In this framework, the primary layer is the vision and mission of the organization which should be strategic which identify the competencies to achieve business goals. These vision and mission statement helps to design KM roadmap.

Next layer contains Accelerators - It means people, process, leadership and technology.

Knowledge Process include identify, create, store, share, application of knowledge.

Outcomes -they are growth, productivity, quality, profitability [10].

\section{9) CBKM framework (case based KM):}

It consists of four main processes as create, understand distribute and reuse. The diagram below is the core diagram for case based KM framework.

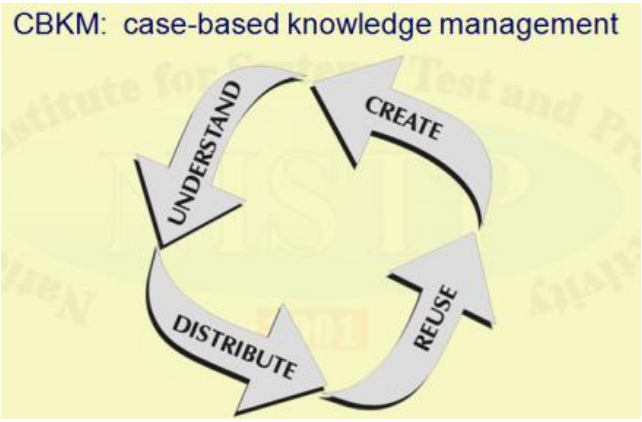

Figure 8: Case based KM 


\section{International Journal of Science and Research (IJSR) \\ ISSN (Online): 2319-7064}

Index Copernicus Value (2013): 6.14 | Impact Factor (2015): 6.391

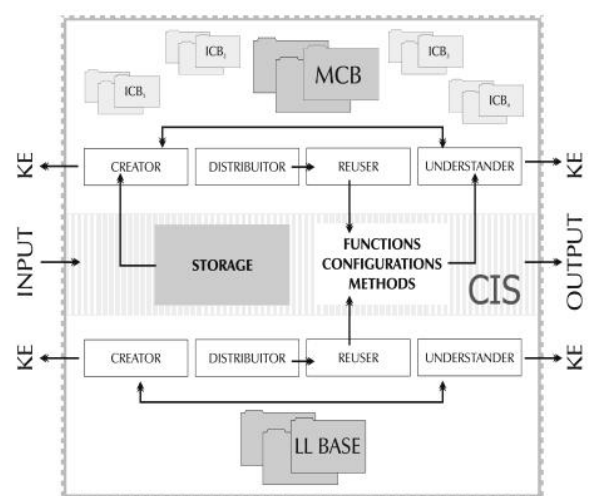

Figure 9: (case based KM)

The above diagram explains the actual component of case based knowledge management framework. Main components of this framework are

1) $\mathrm{MCB}$ - main case base

2) ICB -individual case base

3) Lessons-learned module to learn from external experiences

a. Main LL base

b. Individual LL base

This framework is based on

Monitored Distribution (MD)- Proactive distribution of knowledge artefacts

Knowledge artefacts: lessons learned, alerts

Case-based Reasoning (CBR) - Case-based reasoning (CBR), broadly construed, is the process of solving new problems based on the solutions of similar past problems. An auto mechanic who fixes an engine by recalling another car that exhibited similar symptoms is using case-based reasoning [11].

10) KM framework of supply chains:

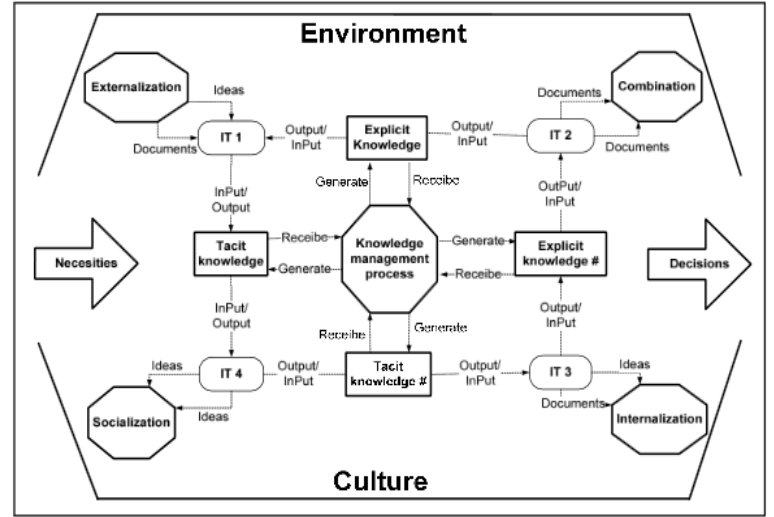

Figure 10: KM framework of supply chains

This framework uses UML based approach and considers six elements.

a) Inputs/outputs: for information technology programmes in terms of explicit or tacit form.

b) Environment/culture: space of interaction among entities. This is governed by the factors applicable for knowledge generation. c) KM process: validation of intangibles and knowledge through documents and used for establishing improvements.

d) Knowledge types: These types (tacit, explicit, tacit \#, explicit \#) are related with input and output through KM process.

e) Input/output connectors: For better action control what knowledge is provided and what is created.

f) Technological information tools: these tools contain architectures used for decision making process [12]

11) The Lotus Knowledge Management Framework:

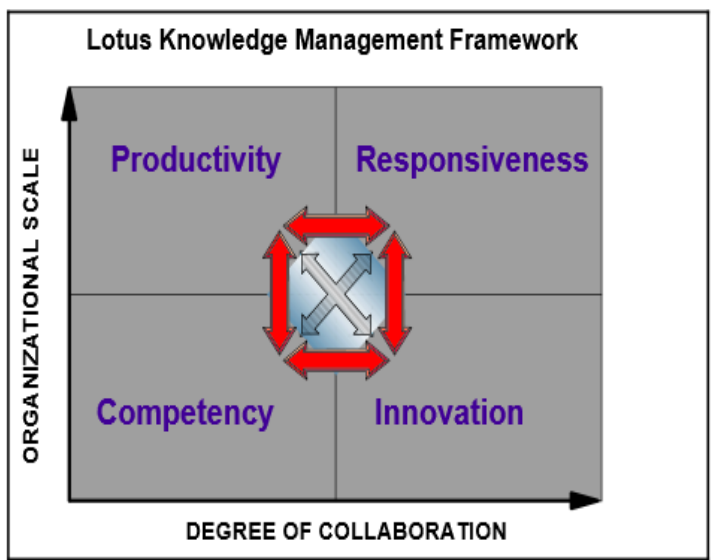

Figure 11: The Lotus Knowledge Management Framework

This framework identifies four basic business goals.

a) Innovation: innovation is always necessary for sustainable development of business. Employee in a company in different geographical location can come together through chatting, brainstorming, sharing ideas and through network. Different collaborations activities are used in innovation.

b) Competency: to become competitive with other companies a company must stay with both the peoples experienced and new comers. New comers must learn the company process by reading, browsing, studying and apprenticing with mentors. Accelerating such activities is a successful KM.

c) Productivity: knowledge assets can be effectively documented so that left hand will learn what right hand is doing. For this knowledge in business process can be reused, discovered, optimized and mining can be done.

d) Responsiveness: Changes in technology helped a lot for improvement in business. By finding questions to answers that who, what when and where a company can quickly coordinate between its activities and give response to customer such as problem solving, strategize, coordination and mass customization [13]

12) KM framework at National Aeronautics and Space Administration (NASA):

People, Process and Technology are the three main component of KM framework at NASA [14]. 


\section{International Journal of Science and Research (IJSR) \\ ISSN (Online): 2319-7064}

Index Copernicus Value (2013): 6.14 | Impact Factor (2015): 6.391

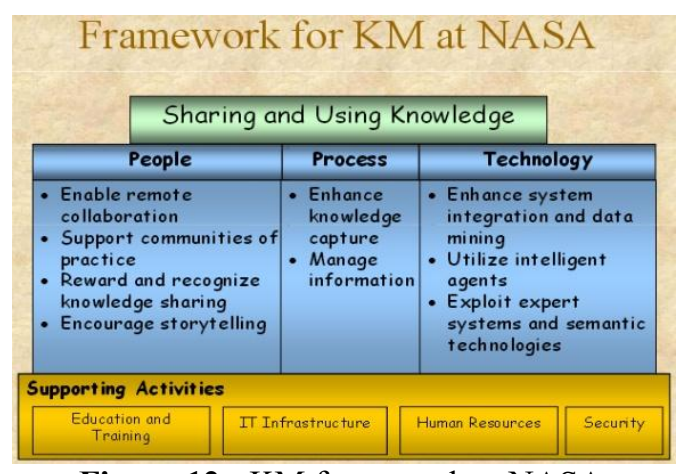

Figure 12: KM framework at NASA

\section{3) Global KM framework:}

This framework describes components and influence factors of KM in globally distributed intra- or inter-organizational settings.

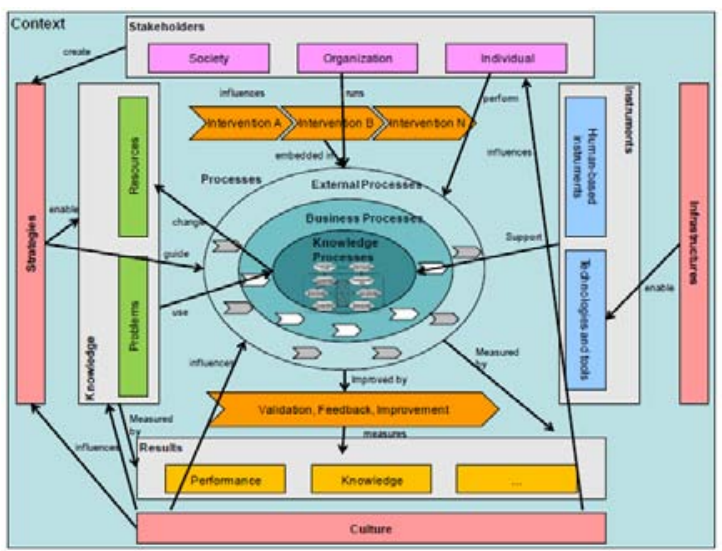

Figure 13: KM framework for international labour organization

The components of the framework are as follows.

a) Processes: It is the core of the framework. These are of three types. Knowledge processes which enable KM within organization, Business Processes (for e.g teaching in education), External processes with external stakeholders such as customers.

b) Stakeholders and contexts: The stakeholder"s components describe the characteristics of participating stakeholders related to individuale $\mathrm{s}$ organizations or societies. Context is the subcategory which describes the environment in which KM takes place.

c) Knowledge: This component describes components of knowledge aspects and information of elements shared within the organization. The interventions are always needed for the resources and problems addressed.

d) Instruments: It describes methods and activities to realize knowledge processes. The main categories are human oriented instruments and technological instruments [15].

e) Results- They is the outcomes of knowledge processes in some form of metrics. They are knowledge, performance, intellectual capital, and global aspects.

There is relation between all these components.

i. Context: It is always seen that the success of the KM projects depends on the context of the organization. ii. Processes: For successful development of $\mathrm{KM}$ projects all the processes must be clearly understood and aligned neatly.

iii. Strategy and management: for high success of $\mathrm{KM}$ the strategy of organization is equally important.

iv. Instruments: The balanced combination of instruments having good influence on success of KM process [16].

\section{4) KM framework for international labor organization:}

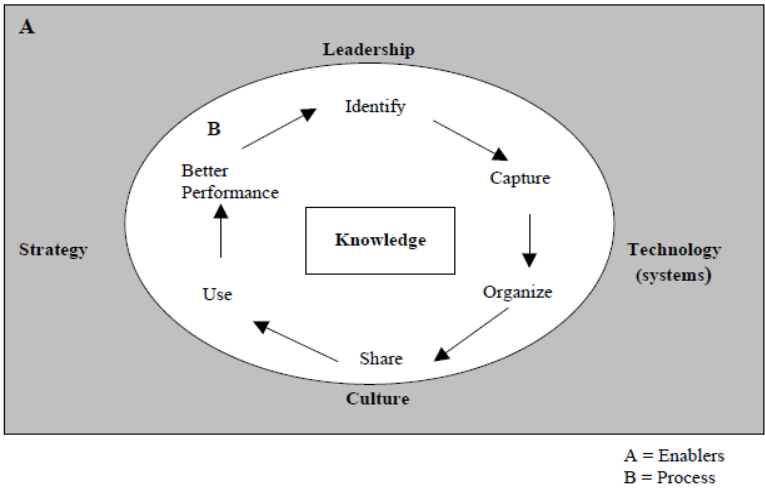

Figure 14: KM framework for international labour Organization organization

This framework consists of two parts A) Enablers B) Process

A) Enablers - Strategy \& Leadership, Culture, and information technology

a. Strategy \& Leadership: every organization has its own strategic framework, but these frameworks are dynamic as the policies of top management may alter according to business competitiveness.

b. Culture: organization "s culture is one of the influencing factors on $\mathrm{KM}$ in terms of knowledge sharing. Due to „knowledge is power" paradigm people hesitate to share the knowledge. Though organizations are having their own culture by encouraging peoples, providing incentives, recognizing and reward system peoples can be used to promote success for knowledge sharing.

c. Information and communication technology They act as catalyst for KM. K-base can be created and accessed through VPN, email, networking infrastructure, SAN(storage area network), linking all operations in a organization for successful knowledge sharing.

B) Knowledge Management Process-

a. General issue (KM responsibility- Knowledge Manager/ Chief Knowledge officer) - in an organization there should be a knowledge manager who takes the responsibility for managing the knowledge.

b. Steps

i. Identification of required as well as available information/ knowledge from different stakeholders was found by many methods such as questionnaires, surveys.

ii. Information/knowledge capture- tacit knowledge can be captured from other organizations from their best practices. 


\section{International Journal of Science and Research (IJSR) \\ ISSN (Online): 2319-7064 \\ Index Copernicus Value (2013): 6.14 | Impact Factor (2015): 6.391}

iii. Organizing scattered information / knowledge to create knowledge assets- this scattered information is organized in data repositories, data warehouses, which should be periodically updated and quickly retrieved when needed.

iv. Sharing of knowledge- Through training, guiding, equipping staff with different computerized tools and techniques in user friendly manner knowledge is shared.

v. Use of knowledge for planning, programming and budgeting and - evaluations of knowledge are carried out manually and automatically. Then these evaluations are processed into knowledge assets so that they can be shared widely [17].

15) KM framework for tourism crisis management:

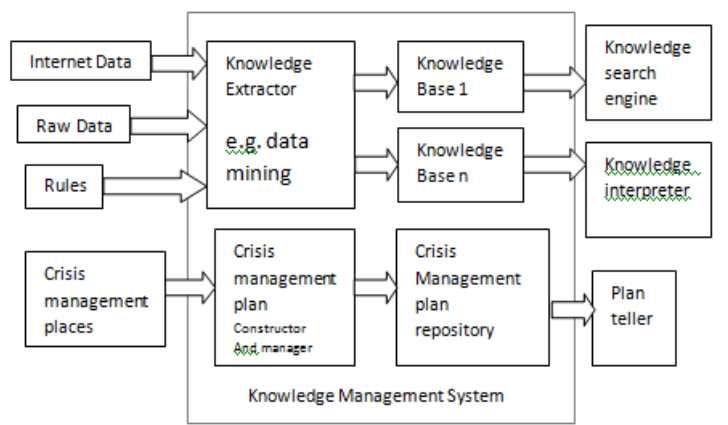

Figure 15: KM framework for tourism crisis management

Zhiyang Jia et al.(2012) has suggested a framework based on AI and web based technologies, which is a software system for tourism crisis management. This framework identifies types of knowledge resources, the basic activities or procedures which have impact on KM and the ways in which this knowledge can be applied in crisis situation of tourism management. This framework is based on contrasting organization knowledge approach for acquisition and storage, retrieval, dissemination, application, evaluation and interaction of knowledge. This knowledge communicates with phases of crisis efficiently. This framework has set of

a) software systems- for knowledge dissemination

b) AI such as decision trees, NN- extraction of raw data and representation in XML

During the stages of crisis historical data is scanned and set of rules are defined, structure data from experts, documents are input to the framework. Through knowledge extractor and crisis management planning knowledge repository is created and shared. After this potential list of scenarios is established with probabilities and decision can be taken [18].

\section{6) KM framework for government organization}

Dr Mishra has provided a framework for KM initiative in the government sector in India. This framework is based on four pillars people, Process, technology and management (PPTM). To implement this framework following guiding principles are defined by author. After implementing the framework knowledge sharing will become power.

\section{PEOPLE-}

a) Launch an intensive awareness campaign- employees in the organization must know $\mathrm{KM}$ initiatives and its advantages. b) Formulate necessary policies to institute a reward system- awards will be given to employees for acquiring more knowledge.

c) Highly publicize the KM success- by doing these employees will be recognized in the organization.

d) Make KM part of the regimen- use of $\mathrm{KM}$ portal, emails, knowledge resources, access to experts, record of lessons learned will make $\mathrm{KM}$ as a part of daily schedule

e) Develop and nurture communities of practice (Cop)employees working at different departments of the same organization on similar work share their knowledge at knowledge centers.

PROCESS- those are the techniques which are used to manage the knowledge. Some changes will be suggested by the author for KM life cycle.

a. Accumulate - knowledge domains will be identified for the areas where KM will have positive impact in the performance of the organization. Knowledge gaps within different units of the organization and its external environment will be identified. New knowledge may be created by using different research methodology techniques.

b. Evaluate-evaluation and validation of knowledge can be done so that knowledge repository will act as central warehouse.

c. Disseminate- explicit knowledge can be codified. Taxonomy of knowledge can be created and knowledge can be stored in appropriate medium. Both tacit and explicit knowledge can be shared wherever and whenever required.

d. Improve- knowledge repositories can be constantly improved for their relevance.

e. Protect- access privileges must be given to protect the repository.

f. Apply- all these activities must result is in usage of knowledge assets by employees.

TECHNOLOGY - ICT, Software design and development, networking, internet services, www services, training, video conferencing are the different technologies through which $\mathrm{KM}$ can take place.

MANAGEMENT- Issues faced by top management will make decision to begin KM in organization.

The outcome of this framework will be the intranet portal for $\mathrm{KM}$ in government organization [19].

17) A Knowledge Management Framework in Software Requirements Engineering Based on the SECI Model:

To facilitate the collaboration among stakeholder and analyst, $\mathrm{KM}$ is used in software requirement engineering. The tacit and explicit knowledge in a software project is managed with four sub systems of this model as "Socializer", "External- izer", "Combiner" and "Internalizer". i.e SECI which is attached to a couple of domain ontologies and a set of knowledge assets. The components are explained as follows.

1) Domain Ontologies: It contains two domain related concepts and relationships namely Application Domain Ontology and Software Requirements Ontology. Semantic relations can model conflicts or dependencies between software requirements. 


\section{International Journal of Science and Research (IJSR) \\ ISSN (Online): 2319-7064}

Index Copernicus Value (2013): 6.14 | Impact Factor (2015): 6.391

2) The knowledge repository: it is composed of knowledge assets in terms of practical and theoretical knowledge. This knowledge assets are definite complete, consistent and ready to share and use.

3) Four virtual Ba's: It offers set of complementary tools that has input as tacit or explicit knowledge which is related to software requirement. Virtual $\mathrm{Ba}$ is coupled to an Integrated Development Engineering Framework.

a) Socializer: It is a set of communication, argumentation and voting tools, emails, forums, chatting tools.

b) Externalizer: It is a set of semantic tools, wikis, CAD tools, prototyping tools used for building prototype.

c) Combiner: It is set of reuse based authoring tools such as fusion, merging, and synthesis services.

d) Internalizer: It is a set of active reading tools such as semantic wikis for structured and unstructured data which is linked to knowledge of domain [20].

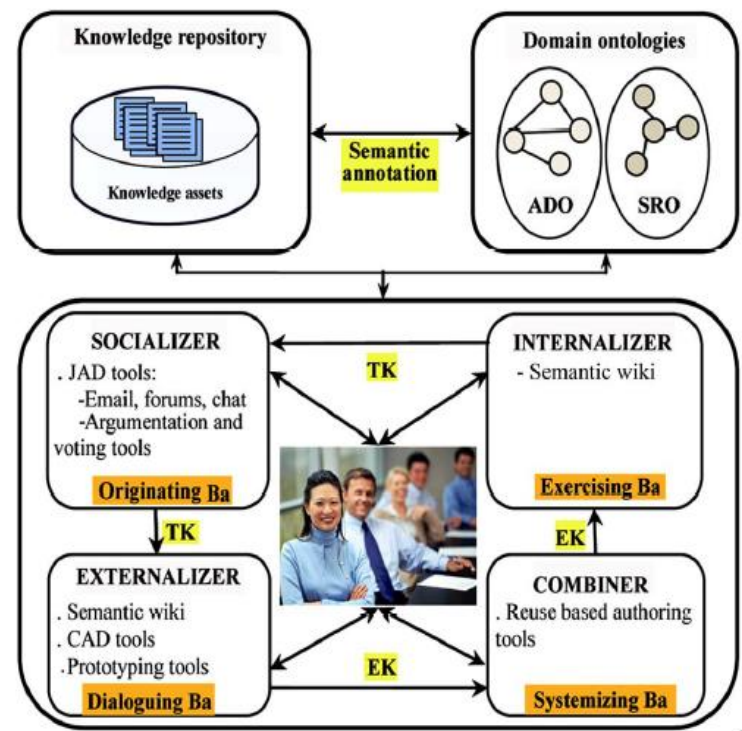

Figure 16: A Knowledge Management Framework in Software Requirements Engineering Based on the SECI Model

18) Knowledge management framework using business intelligence solutions

In the dynamic environment of business interaction with customers plays an important role as services provided in shortest possible time. The proposed framework uses BI tools, data mining and warehousing tools to fulfil customers with comprehensive output. This framework is divided into three stages [21].

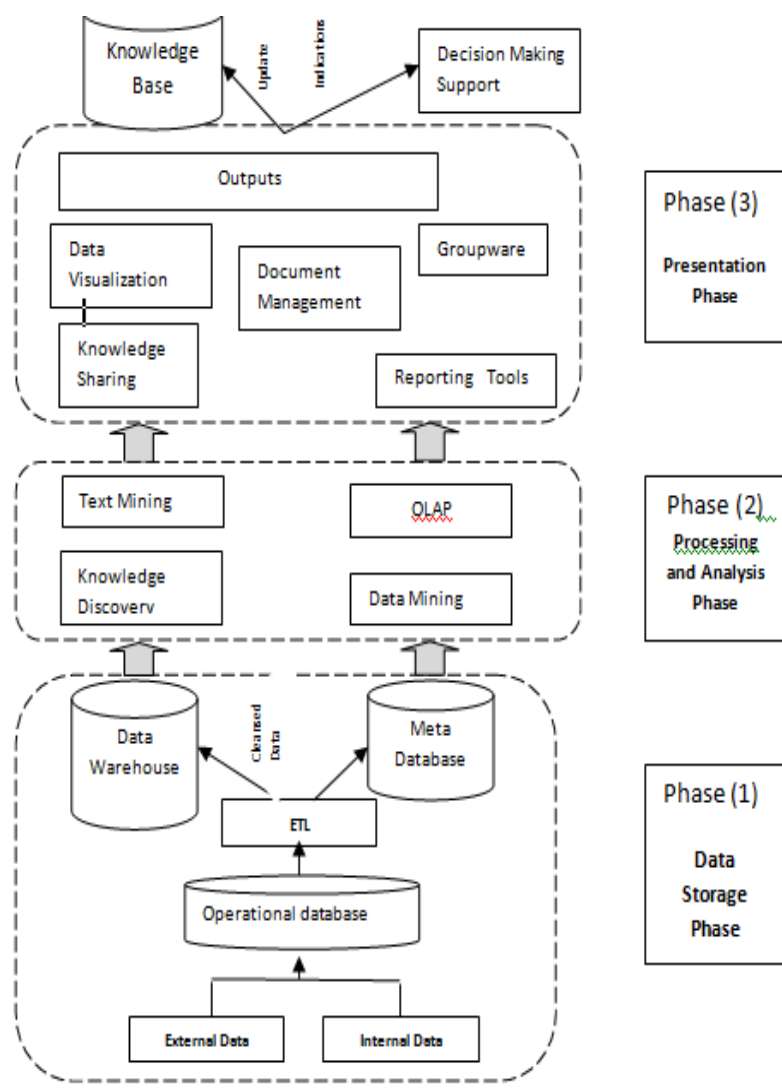

Figure 17: A Knowledge Management Framework using business intelligence solutions

Table 1: Three stages of Km framework for business management framework

\begin{tabular}{|c|c|c|c|}
\hline Phases & Input & Output & Process Description \\
\hline $\begin{array}{c}\text { Data } \\
\text { storage } \\
\text { phase: }\end{array}$ & $\begin{array}{l}\text { Internal data: } \\
\text { about } \\
\text { organization, } \\
\text { employees } \\
\text { External data: } \\
\text { customers, } \\
\text { suppliers, } \\
\text { Govt. agencies }\end{array}$ & $\begin{array}{c}\text { Cleaned } \\
\text { data given } \\
\text { to DW }\end{array}$ & $\begin{array}{c}\text { Data is stored in } \\
\text { operational systems } \\
\text { which process daily } \\
\text { transactions. Using ETL } \\
\text { technology required data } \\
\text { for analysis is loaded } \\
\text { into Data Warehouse. }\end{array}$ \\
\hline $\begin{array}{c}\text { Processing } \\
\text { and analysis } \\
\text { phase }\end{array}$ & $\begin{array}{l}\text { Cleansed data } \\
\text { from DW }\end{array}$ & knowledge & $\begin{array}{c}\text { Function of BI and KM } \\
\text { will work together and } \\
\text { does analysis. } \\
\text { Knowledge extraction } \\
\text { from data will be done }\end{array}$ \\
\hline $\begin{array}{c}\text { Presentation } \\
\text { phase }\end{array}$ & Knowledge & $\begin{array}{c}\text { Summary } \\
\text { reports, } \\
\text { graphs }\end{array}$ & $\begin{array}{l}\text { Representation of reports } \\
\text { in various forms like } \\
\text { document management, } \\
\text { visualization tools for } \\
\text { decision making phase. } \\
\text { Such data is now shared } \\
\text { within the organization }\end{array}$ \\
\hline
\end{tabular}

\section{Conclusion}

This paper gives concrete idea about KM frameworks in various organizations. It is observed that in every framework, knowledge sharing is important. All frameworks are using web concept for knowledge sharing by any means. This shared knowledge will be retrieved by knowledge seekers as per individuals ${ }^{\text {ee }}$ need. 


\section{International Journal of Science and Research (IJSR) \\ ISSN (Online): 2319-7064}

Index Copernicus Value (2013): 6.14 | Impact Factor (2015): 6.391

\section{References}

[1] Bhusry M., Rajan J.(2011), Knowledge collaboration in higher educational institutions in India: charting a knowledge management solution, International journal of computer science, 29(1), 975-8887. http://doi.org/10.5120/3527-4805.

[2] Republic, C. (2004). WORKSHOP AGREEMENT, European Guide to good Practice in Knowledge Management - Part 1: Knowledge Management Framework. Knowledge Management, 1-33.

[3] Ezingeard, J-N., Leigh, S. \& Chandler-Wilde, R. (2002), Knowledge management at Ernst \& Young: Getting value through knowledge flows, ICIS 2002 Conference Proceedings.

[4] Arrus K., Hayes J. et al, Knowledge management @ Accenture, also available at: https://www.google.co.in/url?sa $=\mathrm{t} \& \mathrm{rct}=\mathrm{j} \& \mathrm{q}=\& \mathrm{esrc}=\mathrm{s} \& \mathrm{~s}$ ource $=$ web $\& \mathrm{~cd}=2 \& \mathrm{cad}=$ rja\&uact $=8 \&$ ved $=0$ ahUKEwjz 0 L3U45TLAhXHwI4KHSJaC44QFgggMAE\&url=http\% $3 \mathrm{~A} \% 2 \mathrm{~F} \% 2 \mathrm{Fwww}$.umanitoba.ca\%2Ffaculties $\% 2 \mathrm{Fmanag}$ ement $\% 2$ Ffaculty $\% 2$ Fbtravica $\% 2$ F9615\%2FTeam3.ppt \&usg=AFQjCNEVSHnG6Xed88v8udTd7LfXmyheA\&bvm=bv. 115339255 ,d.c2E

[5] Rodige-cnrs, A. P. L. E. M., \& Sophia, N. (1996). Valuing Knowledge Management in Organizations , from theory to practice: the case of Lafarge Group. Knowledge Creation Diffusion Utilization

[6] B. kari, I toru,2006, knowledge management

[7] Dr, Thuraisingham B. (2010) ,KM semantic web and networking, knowledge management.

[8] http://www.ksslibraries.nhs.uk/elearning $/ \mathrm{km} / \mathrm{kmf} / \mathrm{km}$ fr amework

[9] Source Geoff Parcell (2009), Parcell, Geoff (2009) Lecture notes, Knowledge Management for Development Conference, 9-13 Windhoek, Namibia

[10] Sensuse, D. I., \& Rohajawati, S. (2013). Knowledge Management: Workshop APO Framework ( Case Study: Ministry of Religious Affairs of Republic Indonesia ). International Journal of Computer Science, 10(2), 25-32

[11]R. Weber, Eight IEEE symposium on HIGH ASSURANCE SYSTEM ENGINEERING 25,26 march 2004" knowledge management for computational intelligence systems .

[12] Hernandez, J. E., Poler, R., Mula, J., \& Peidro, D. (2008). A collaborative knowledge management framework for supply chains: A UML-based model approach. Journal of Industrial Engineering and Management, 1(2), 77-103. http://doi.org/10.3926/jiem.2008.v1n2.p77-103

[13]Lotus , IBM , and Knowledge Management January 1998 A Lotus Development Corporation Strategic White Paper. (1998). Knowledge Management, (January).

[14] Murphy, K., \& Holm, J. (2008). Knowledge Management at NASA: Supporting Missions and Collaboration Why Is KM Critical to NASA ?

[15] Maier, R. (2007) Knowledge Management Systems: Information and Communication Technologies for Knowledge Management, 3rd ed. Springer, Berlin et al.

[16] Pawlowski, J.M., Bick, M. (2012): The Global Knowledge Management Framework: Towards a Theory for Knowledge Management in Globally Distributed Settings, Electronic Journal of Knowledge Management.

[17] Joint Inspection Unit ,Geneva Knowledge Management At the international labour organization. (2004). Knowledge Management.

[18] Jia, Z., Shi, Y., Jia, Y., \& Li, D. (2012). A framework of knowledge management systems for tourism crisis management. Procedia Engineering, 29, 138-143. http://doi.org/10.1016/j.proeng.2011.12.683

[19]Mishra D., et.al,(2003), information systems management, E-knowledge management for government organizations, SPRING, pp 46-47

[20]Chikh, A. (2011). A Knowledge Management Framework in Software Requirements Engineering Based on the SECI Model. Journal of Software Engineering and Applications, 04(12), 718-728. http://doi.org/10.4236/jsea.2011.412084

[21] Gadu, M., \& El-khameesy, P. N. (2014). A Knowledge Management Framework Using Business Intelligence Solutions, International journal of computer science, 11(5), 102-108.

[22] Heisig, P.," Harmonization of knowledge management160 comparing 160 frameworks along globe ", Journal of Knowledge Management, vol. 13, No.4, p.p.4-31.

\section{Author Profile}

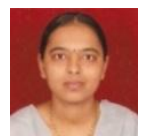

Dipali Meher has completed her Masters in Computer Science from SP Pune University and M.Phil in Computer Science from YCMOU. Currently she is pursuing Ph.D from IMED, Bharti Vidyapeeth Deemed University. She is currently working as Assistant Professor at Department of Computer Science, Modern College Ganeshkhind, Pune. She has 12 years of teaching experience at UG and PG level. She also holds variety of crucial positions like External Senior Supervisor, Chairman of Paper Setting Board, Visiting faculty.

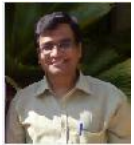

Dr. Nilesh Mahajan has excellent academic background. Currently he is working as Professor at IMED, Bharti Vidyapeeth Deemed University, Pune. $\mathrm{He}$ is currently guiding 8 research students on subjects like knowledge management, cloud computing, data mining, fuzzy logic and Big data. He also holds variety of crucial positions like External Senior Supervisor, Member of Board of Studies and many more. 